\title{
Coordination of eye and head movements during smooth pursuit in patients with vestibular failure
}

\author{
John A Waterston, Graham R Barnes, Madeleine A Grealy, Linda M Luxon
}

\begin{abstract}
During pursuit of smoothly moving targets with combined eye and head movements in normal subjects, accurate gaze control depends on successful interaction of the vestibular and head movement signals with the ocular pursuit mechanisms. To investigate compensation for loss of the vestibulo-ocular reflex during head-free pursuit in labyrinthinedeficient patients, pursuit performance was assessed and compared under headfixed and head-free conditions in five patients with isolated bilateral loss of vestibular function. Target motion consisted of predictable and unpredictable pseudo-random waveforms containing the sum of three or four sinusoids. Comparison of slow-phase gaze velocity gains under head-free and head-fixed conditions revealed no significant differences during pursuit of any of the three pseudorandom waveforms. The finding of significant compensatory eye movement during active head movements in darkness in labyrinthine-deficient patients, which were comparable in character and gain to the vestibular eye movement elicited in normal subjects, probably explains the similarity of the head-fixed and head-free responses. In two additional patients with cerebellar degeneration and vestibular failure, no compensatory eye movement response was observed, implying that the cerebellum is necessary for the generation of such responses in labyrinthine-deficient patients.
\end{abstract}

(F Neurol Neurosurg Psychiatry 1992;55:1125-1131)

MRC Human

Balance Unit, National

Hospital for Neurology

and Neurosurgery,

Queen Square,

London

J A Waterston

G R Barnes

M A Grealey

Neuro-otology Unit

L M Luxon

Correspondence to:

Dr G R Barnes, MRC

Human Movement and

Balance Unit, National

Hospital for Neurology and

Neurosurgery, Queen

Square, London WCIN

3BG.

Received 1 November 1991

and in revised form

Accepted 10 March 1992 compared to the unstable images produced by a movie camera which is moved about randomly at high frequency. ${ }^{1}$ Despite these problems, many patients who are initially quite disabled by loss of vestibular function, subsequently demonstrate remarkable adaption and are able to return to near normal lifestyles with few visual complaints.

Studies of gaze control in labyrinthinedeficient (LD) patients and monkeys have revealed a variety of adaptive mechanisms which may be used to compensate for loss of the VOR during self-motion or rapid gaze shifts. These include potentiation of the pursuit, $^{2}$ optokinetic, ${ }^{2-4}$ and cervico-ocular reflexes, ${ }^{5-8}$ the use of somatosensory cues, and the central pre-programming of eye movements. ${ }^{2568}$ There have been relatively few studies of head-free pursuit performance in these subjects. During pursuit with the head free it is necessary to suppress the VOR which would normally produce eye movements of opposite polarity to head movement. It has been postulated that, during head-free pursuit, a central suppression mechanism incorporating an efference copy of the planned head velocity signal, is used to cancel the VOR. ${ }^{10}$ One prediction of this model is that, in patients with loss of vestibular function, tracking gains should exceed unity during head-free pursuit if cancellation were still in operation, even though there is no significant vestibular response. ${ }^{10}$ Previous studies in normal subjects over limited ranges of motion have shown little difference in tracking performance between head-free and head-fixed pursuit. ${ }^{11-14}$ In contrast, it has been shown that head-free pursuit of predictable sinusoidal target motion produced better slow-phase tracking gains compared with pursuit with the eyes alone in labyrinthine-deficient patients. ${ }^{13}$ The differences demonstrated were not marked and the gains never exceeded unity because of the presence of compensatory eye movements (CEM) which simulated the normal VOR. Performance during pursuit of unpredictable target motion has not been assessed in these patients.

To explore the mechanisms that compensate for loss of the VOR during head-free pursuit, we have examined the responses to pursuit of pseudo-random target motion in deficient patients, under head-free and head-fixed conditions, using a stimulus consisting of the sum of three or four sinusoids. By adjusting the velocities and frequencies of the components in the pseudo-random stimulus it is possible to produce both predictable and unpredictable 
Table Clinical features of labyrinthine-deficient patients .

\begin{tabular}{llll}
\hline Number & Age/sex & Aetiology & Duration (years) \\
\hline 1 & $49 / \mathrm{M}$ & Post-infectious & 14 \\
2 & $59 / \mathrm{F}$ & Syphilis & 10 \\
3 & $59 / \mathrm{M}$ & ?Vascular & 3 \\
4 & $52 / \mathrm{F}$ & Idiopathic & 9 \\
5 & $25 / \mathrm{M}$ & Idiopathic & 18 \\
\hline
\end{tabular}

target motion. ${ }^{1516}$ We have also measured the CEM gain in the patients during active head movements in darkness because, if these eye movements are of sufficiently high gain, they will influence head-free pursuit performance. The study of two patients with degenerative neurological diseases, characterised by cerebellar degeneration in addition to loss of vestibular function, provided an opportunity to explore the possible relationship between cerebellar pathways and the genesis of the CEM responses.

\section{Materials and methods \\ Patients}

Five patients with isolated bilateral loss of vestibular function, as demonstrated by caloric and rotational testing, were studied. Their details are summarised in the Table. Patients were excluded if there was any central disorder of eye movement evident, such as smooth pursuit breakdown or slowing of saccades, or if they were taking sedatives or anticonvulsant drugs, which are known to impair smooth eye movement control. One subject with absent responses on caloric testing was later excluded because of the finding of significant residual function on sinusoidal rotation, an apparent disparity alluded to by previous authors. ${ }^{131718}$ All patients had longstanding vestibular failure and were clinically well compensated.

Two additional subjects with degenerative neurological conditions characterised by relatively pure combined loss of vestibular and

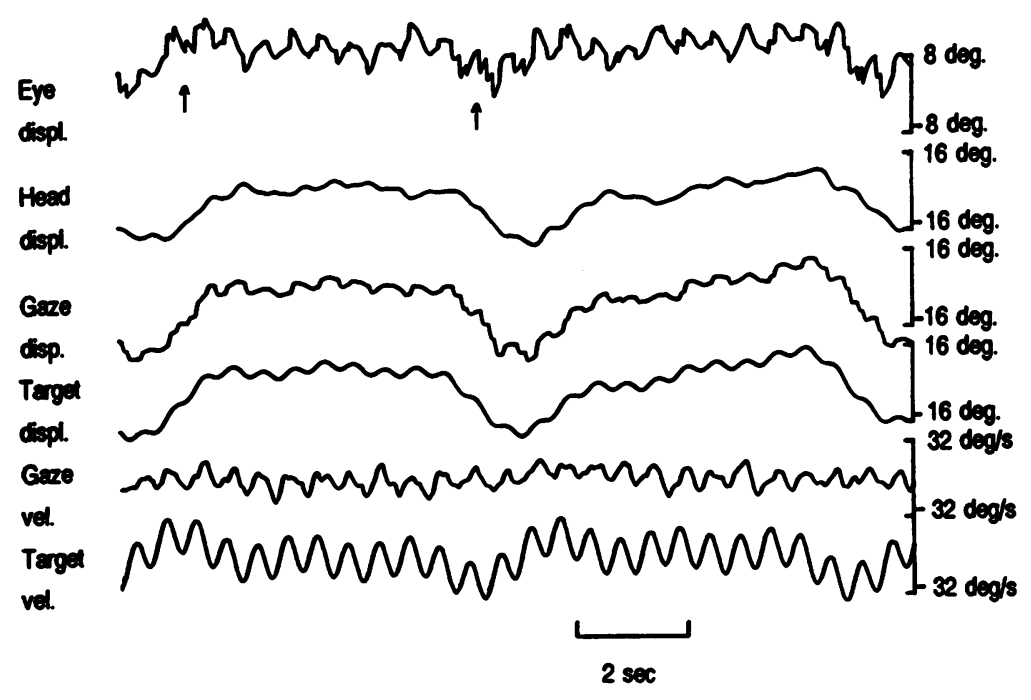

Figure 1 Traces of eye, head, gaze and target displacement, and gaze velocity during head-free pursuit of pseudo-random target motion from $L D$ patient. The stimulus contained $0.11,0.24,0.37$ (peak velocity $8 \%$ s) and $1.56 \mathrm{~Hz}$ sinusoids (peak velocity $16 \%$, i.e. velocity ratio of $t w 0$ ). The fast phases have been removed from the gaze velocity trace. The arrows below the eye displacement trace mark clear examples of unsuppressed CEM activity, similar in character to the vestibular activity observed in normal subjects. cerebellar function were also investigated. Some of their clinical features were reminiscent of multiple system atrophy or olivopontocerebellar atrophy, but there was no other clinical evidence of brain stem, cortical, extrapyramidal or autonomic involvement, and family history was negative. The exact nature of their disease was unknown, but CT of the brain showed evidence of cerebellar atrophy in both patients. A group of normal, naive, agematched subjects acted as controls, and all experiments were carried out with local ethics committee approval.

\section{Apparatus}

Subjects were seated comfortably in front of a semicircular screen of radius $1.5 \mathrm{~m}$. A motordriven mirror situated above the subject's head was used to drive the target, a small white cross within a circle whose diameter subtended 70 minutes of arc at the eye. Eye movements were recorded using an infrared limbus reflection technique (Iris 6500 system, Skalar Medical) with a resolution of 10 minutes of arc and a linear range of at least plus or minus $20^{\circ}$. The recording equipment was mounted on a helmet assembly which was attached firmly to the subjects head, so that no movement occurred between the eye recorders and the head. A single turn potentiometer, attached to the top of the helmet via a flexible assembly, was used to record head movements. Vestibular function was assessed during sinusoidal oscillation about an earth vertical axis on a motorised turntable (Toennies, $200 \mathrm{Nm}$ ).

\section{Experimental design}

Each experiment was presented in a balanced randomised fashion to control for practice or fatigue effects. Calibrations were performed before each test condition. All experiments were carried out in a room which, apart from target illumination, was otherwise completely dark.

Experiment 1 A pseudo-random stimulus containing the sum of three or four sinusoids $(0.11,0.24,0.37$ and $1.56 \mathrm{~Hz})$ was used for the pursuit task (fig 1). The velocity of the three lower frequency sinusoids remained constant at $8 \%$, whereas the velocity of the 1.56 $\mathrm{Hz}$ component was varied as a ratio of the lower frequency velocity (velocity ratio) between zero and two. Thus the $1.56 \mathrm{~Hz}$ component was absent when the velocity ratio was zero. Previous studies have demonstrated that, when a pseudo-random stimulus contains frequency components which are all less than a critical level of $0.4 \mathrm{~Hz}$, the target motion is very predictable. The addition of a sinusoid whose frequency is greater than $0.4 \mathrm{~Hz}$, however, results in a reduction in gain of all the lower frequency components. Further breakdown at the lower frequencies occurs when the velocity of the high frequency is increased. ${ }^{16}$ These changes are accompanied by preferential enhancement of gain at the highest frequency, such that the gain at this frequency is similar to the gain obtained during pursuit of a single sinusoid of the same frequency. ${ }^{15}$ The breakdown in the low frequency responses occurs 

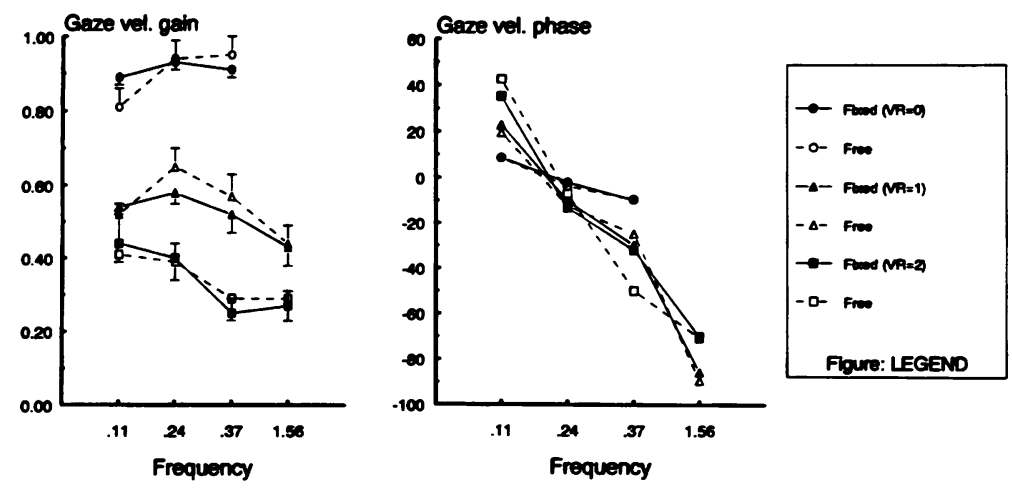

Figure 2 Slow-phase gaze velocity gain and phase in labyrinthine-deficient subjects during a comparison of head-fixed (solid line) and head-free (broken line) pursuit of a pseudo-random target containing the sum of three $(0.11,0.24$ and $0.37 \mathrm{~Hz})$; or four $(0.11,0.24,0.37$ and $1.56 \mathrm{~Hz})$ sinusoids. The peak velocity of the three lowest frequency components was held constant at $8 \%$, whereas the peak velocity of the $1.56 \mathrm{~Hz}$ component was varied as a velocity ratio of the lower frequency velocity between zero and two (resulting in peak velocities of 0,8 or $16 \%$ ). Each single line plot represents the individual gains for each of the frequency components contained in one stimulus (total of three head-fixed, and three head-free stimuli). Mean (SE 1) $(n=5)$.

essentially as a result of making the waveform less predictable, and allows for comparisons to be performed during both predictable and unpredictable target motion at normal frequencies of eye and head movement. Subjects were asked either to track the target using eye movements only, or to use the eyes and head together in a natural fashion.

Experiment 2 During this experiment, the gain of the CEM response was measured by recording the eye movements associated with active head movements in darkness. Sinusoidal responses at each of the three lower frequencies used in the pseudo-random stimulus $(0.11,0.24$, and $0.37 \mathrm{~Hz})$ were assessed. Each had a peak velocity of $16 \%$ to approximate the RMS velocity of the pseudo-random waveform. Subjects were initially asked to track the target with the head free, in time with a sinusoidally modulated tone placed above the subject's head. The target was then extinguished and subjects were asked to imagine that they were still tracking the target in the dark in time with the tone. Previous studies have demonstrated that this paradigm results in little, if any, suppression of the VOR. ${ }^{121419}$ An observer monitored head movements on an
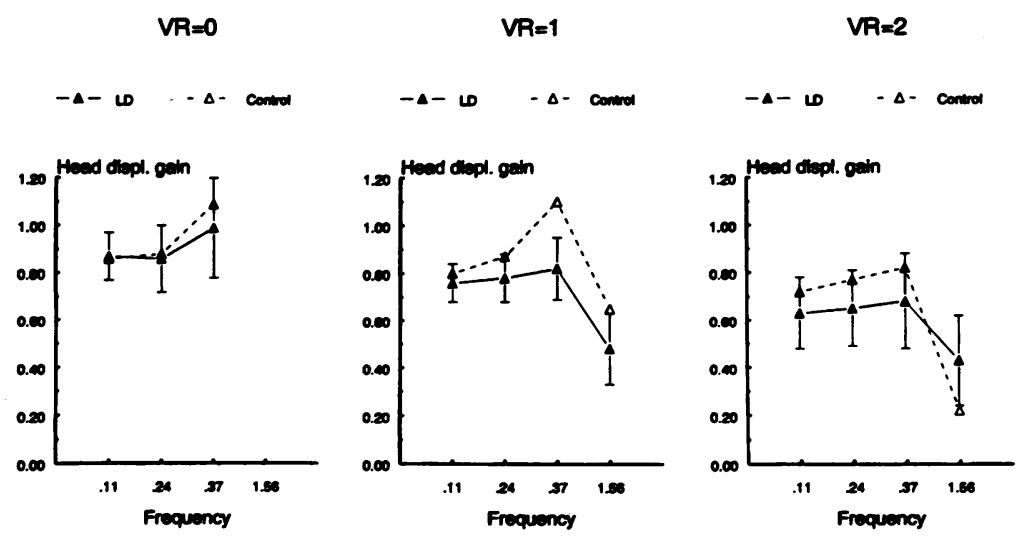

Figure 3 Head displacement gain during head-free pursuit of the pseudo-random stimulus for labyrinthine-deficient patients (solid line) and control subjects (broken line). Mean (SE 1) for deficient patients $(n=5)$. oscilloscope screen and prompted the subject if the movements were inappropriately large or small. The order of the above conditions was maintained, but the frequencies were presented in random fashion. A measure of residual VOR gain was also obtained for comparison, during whole body turntable rotation in the dark at the same frequencies and velocities, while subjects performed mental arithmetic to maintain alertness. In addition, recording of saccadic velocities in the two patients with cerebellar degeneration was performed at amplitudes of up to $30^{\circ}$ using a visually elicited saccade paradigm, to look for possible evidence of brain stem involvement.

\section{Experimental control and analysis}

All experiments were controlled and analysed off line by computer (Hewlett-Packard $360 \mathrm{CH}$ ) using techniques described previously. ${ }^{15}$ Gaze displacement was calculated by summing eye and head displacement, and gaze velocity was obtained by differentiating gaze displacement. A computer graphics procedure was used to remove the saccadic components from the gaze velocity trace. ${ }^{20}$ The resultant measure of slow-phase gaze velocity was then correlated with target velocity to produce gaze velocity gain and phase. All subsequent references to gaze velocity refer to slow-phase gaze velocity. Statistical significance was assessed by analysis of variance.

\section{Results \\ Experiment 1}

During head-fixed pursuit of the pseudorandom stimulus composed of the three lowest frequency sinusoids $(0.11,0.24$ and $0.37 \mathrm{~Hz}$, there was no significant difference between the eye velocity gains for labyrinthine-deficient (mean 0.91) and control subjects (mean 0.94). The gains for each frequency component for this combination of frequencies have previously been shown to be similar to the gains obtained during pursuit of single sinusoidal target motion at the same frequencies, as long as all the components are less than a critical level of $0.4 \mathrm{~Hz} .{ }^{15}$ When the $1.56 \mathrm{~Hz}$ sinusoid was added to the stimulus, and when its velocity was increased with respect to the other frequency components, there was a progressive decrease in gain at all the lower frequencies, and again there was no significant difference between the patient and control groups (for example, mean gain was 0.34 for the patient group and $\mathbf{0 . 3 8}$ for controls when the velocity ratio was two). The phase changes were also similar to those reported previously in normal subjects, with an increasing phase lead at the lowest frequency, and increasing phase lags at all other frequencies except the highest frequency which showed a decreasing phase lag as the velocity ratio was increased (fig 2). ${ }^{15} 16$

During head-free pursuit of an identical stimulus, head displacement gain tended to be slightly higher in the control group but the differences were not significant. Mean head displacement gain in the LD group was always greater than 0.62 for the three lowest fre- 

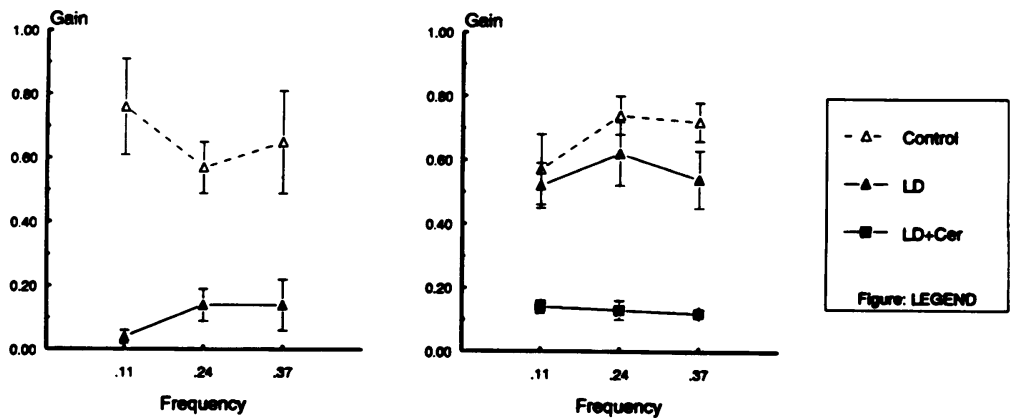

Figure 4 CEM gain for patients (solid line) and control subjects (broken line) during (a) passive sinusoidal turntable motion, and (b) active head movements in darkness. LD $=$ labyrinthine-deficient patients $(n=5), L D+C e r=$ labyrinthine-deficient patients with cerebellar degeneration $(n=2)$. Mean $(S E 1)$.

quencies, but fell to a level of 0.43 at $1.56 \mathrm{~Hz}$ when the velocity ratio was two (fig 3 ). No significant differences were observed when gaze velocity gain was compared under headfixed and head-free conditions (fig 2). Similar breakdowns in gain were observed with increasing velocity ratio under both head conditions, and subjects generally did not experience any subjective difference in performance between the head-fixed or free conditions.

The two patients with cerebellar degeneration showed a similar pattern of breakdown in the lower frequency responses resulting from addition of the high frequency component, but gaze velocity gain was reduced over all condi-

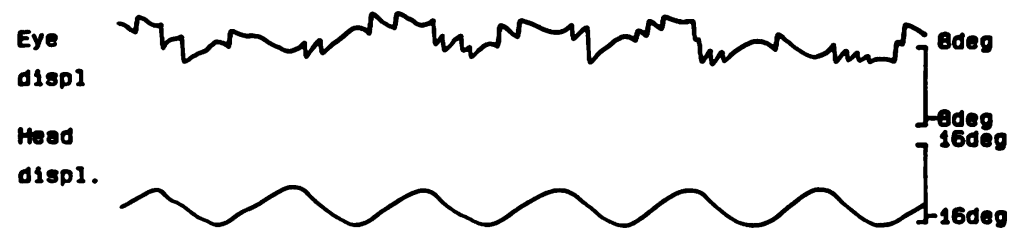

a) Control

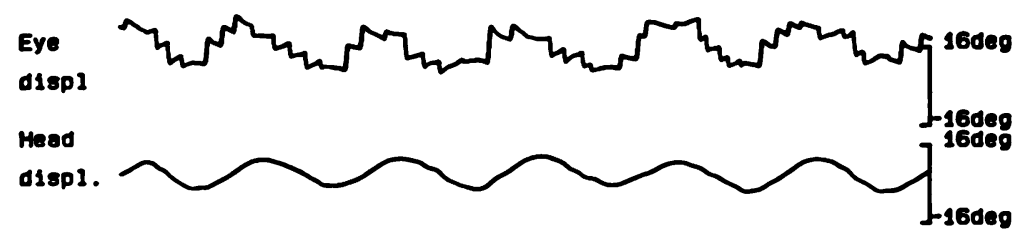

b) LD patient

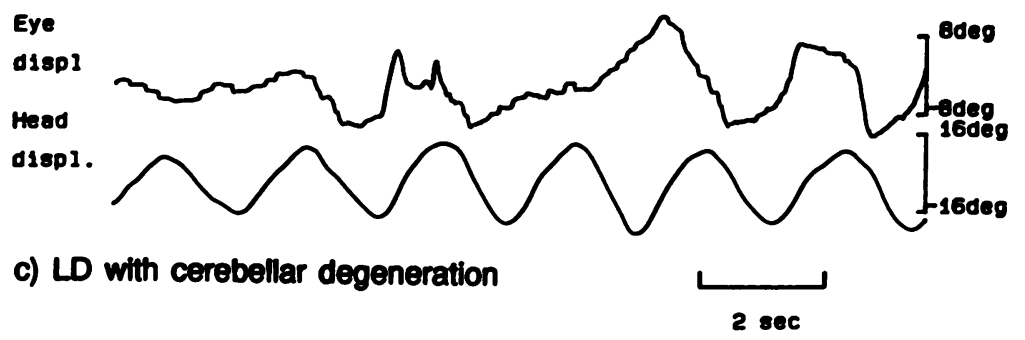

Figure 5 Eye movement traces during active head movements in darkness at $0.37 \mathrm{~Hz}$ from (a) a control subject, (b) a labyrinthine-deficient patient, and (c) a labyrinthine-deficient patient with cerebellar degeneration. Note the presence of vestibular-like CEM activity present in trace (b) but not trace (c). tions as a result of the severe pursuit deficit (means of 0.65 and 0.31 , for velocity ratios of zero and two respectively). Under head-fixed conditions, the much larger amplitudes of eye displacement resulted in a moderate degree of gaze-evoked nystagmus in both patients, with consequent reductions in gaze velocity gain, so a meaningful comparison with the head-free gains could not be performed.

\section{Experiment 2}

The mean VOR gain observed when subjects were asked to make active head movements to track an imaginary target in darkness, ranged between 0.57 at $0.11 \mathrm{~Hz}$ and 0.74 at $0.24 \mathrm{~Hz}$ (mean 0.68 ). These measures approximated the gains obtained during whole-body turntable motion at the same frequencies (mean $0 \cdot 66$ ). Despite the absence of any significant turntable VOR response in the LD subjects, a significant CEM response could be demonstrated during active head movements, which ranged between 0.52 at $0.11 \mathrm{~Hz}$ and 0.62 at $0.24 \mathrm{~Hz}$ (mean 0.56, fig 4). Generally, the pattern of CEM in the patients resembled a normal vestibular response (fig 5) and, although the gains were not as high as those recorded in controls, the differences were not significant. When the recordings from deficient patients during head-free pursuit of pseudorandom target motion were examined, the breakdown in gaze velocity gain with increasing velocity ratio was seen to be associated with inadequate suppression of the CEM response (see fig 1). This activity was often indistinguishable from the unsuppressed vestibular activity observed during similar experiments in normal subjects. ${ }^{1214}$

In the two patients with cerebellar degeneration, no significant CEM response was generated at any frequency (see fig 4). Their eye movement traces consisted of saccades without any major slow-phase components (see fig 5). Examination of the main sequence plots for these patients demonstrated normal peak saccadic velocities at all target amplitudes.

\section{Discussion}

These studies have demonstrated that wellcompensated patients with bilateral loss of vestibular function are able to develop CEM of sufficient gain to influence smooth gaze control during head-free pursuit. As a result, no significant difference in gaze velocity gain was observed between head-fixed and head-free pursuit. In two patients with additional involvement of cerebellar pathways, the CEM responses were absent, suggesting that cerebellar connections are necessary for the production of these responses.

The pattern of eye movement response seen in labyrinthine-deficient subjects during active head movements in the dark is very similar to that reported by others ${ }^{61312}$ and has been attributed in part to enhancement of the cervico-ocular reflex (COR), although not all studies have shown such potentiation. ${ }^{22} 23$ Similar changes have been observed with passive movements, either of the head itself or 
of the trunk with respect to the head, emphasising the importance of the COR in the genesis of this response. ${ }^{62425}$ The gain produced under these conditions is less than that seen during active head movements, particularly at frequencies above $0.2 \mathrm{~Hz}^{8}$ so clearly other compensatory mechanisms are involved, such as central pre-programming of eye movements. 56822

It has been demonstrated previously that impairment of VOR suppression becomes evident as tracking gains fall during head-free pursuit in normal subjects. ${ }^{1121426}$ The contribution to gaze velocity made by the head movement is effectively nulled by the resultant vestibular signal and consequently, gaze velocity is similar whether or not the head moves. It therefore might have been expected that gaze velocity gains would be significantly higher during head-free pursuit in LD subjects, because of the absence of any significant vestibular response. The eyes would only have had to make up the difference between head and target displacement, thereby allowing a potential advantage in the use of head movement. This conclusion is supported by the results of a previous experiment in normal subjects; when the effect of the VOR was artificially attenuated by using whole body turntable motion to oppose head motion during head-free pursuit, significant increases in slow-phase gaze velocity occurred. ${ }^{12}$ In the present study, however, there was no significant difference in gaze velocity gain for head-fixed and head-free pursuit, even at peak target velocities of up to $40 \%$ s. This observation can be explained by the presence of a significant CEM response, resembling the normal VOR, during active sinusoidal head movements in darkness. The mean gains of this response in the labyrinthine-deficient group were only slightly lower than those recorded in the control group (see fig 4).

Leigh et al $^{13}$ previously demonstrated that head-free gaze velocity gains were significantly greater than the corresponding head-fixed gains during pursuit of sinusoidal target motion in deficient subjects, but only at the highest frequency tested $(1.0 \mathrm{~Hz})$. This apparent discrepancy with our results may be explained by the difference in the frequencies assessed. Most of the frequencies used in the present study were less than $0.4 \mathrm{~Hz}$. Although the highest frequency in the pseudo-random stimulus was $1.56 \mathrm{~Hz}$, mean head displacement at this frequency was much lower (see fig 3 ), and the stimulus velocity was significantly less than that used by Leigh et al, so that any small differences in gaze velocity may not have been apparent. We did not measure the gain of the CEM responses at frequencies above 0.4 $\mathrm{Hz}$, but others have shown that the gain begins to fall off at around $1 \mathrm{~Hz}^{2}$ This would explain the absence of symptoms such as oscillopsia during low frequency combined eye and head movements in deficient subjects, and their association with higher frequency head movements such as those produced during walking. ${ }^{27}$ Compensation is therefore usually only satisfactory at lower frequencies, under $1 \mathrm{~Hz}$, and this frequency limitation probably explains the higher head-free tracking gains found at $1.0 \mathrm{~Hz}$ in the previously mentioned study. ${ }^{13}$ The differences found were almost certainly not explained by the pseudo-random stimulus being less predictable than the equivalent sinusoidal waveforms as, when the velocity ratio of the pseudo-random waveform was zero, the stimulus should have been as predictable as each of the individual sinusoidal waveforms contained within the stimulus. ${ }^{15} 16$

In common with the findings of Leigh et al, ${ }^{13}$ head-free pursuit gain never exceeded unity. Gains greater than unity might be predicted from the central suppression model ${ }^{10}$ if head displacement gain was high and patients with loss of vestibular functions were not able to dispense with what, to them, would be an inappropriate suppressive mechanism. An alternative model proposes that the visual feedback mechanisms active during smooth pursuit are responsible for suppression of the vestibular response. ${ }^{2829}$ This model predicts that the head velocity signal will be effectively nulled by the CEM signal if the gain of the latter response is near unity. Within certain limits gaze control will therefore be similar whether or not the head is free to move. ${ }^{11-14} \mathrm{We}$ were still unable to demonstrate a difference between head-fixed and head-free performance despite the fact that the CEM gain was significantly less than unity in both deficient patients and control. This can be explained by the results of previous studies in normal subjects, which demonstrated that the underlying VOR gain during head-free pursuit actually correlated better with the higher gains observed during active head movements in darkness when subjects were asked to imagine an earth-fixed target. ${ }^{1314}$ These gains are usually around a level of 0.9 and this level of gain is very similar to the level of VOR gain observed in normal subjects during the first $150-180 \mathrm{~ms}$ of transient rotations in the light or dark. ${ }^{30}$

It therefore seems that, in compensating for the loss of the VOR, labyrinthine-deficient patients effectively modify their gaze control in such a way as to reduce any difference in performance characteristics between head-free and head-fixed pursuit. The neural signal driving gaze during smooth pursuit would therefore be very similar whether or not the head is moving. Possible neurophysiological correlates of such a signal have been documented in neurons which discharge in proportion to gaze, rather than eye or head velocity, in the primate flocculus. ${ }^{3132}$ We therefore contend that no practical advantage would be served by a parametric reduction or total cancellation of the VOR during head-free pursuit by a central suppression mechanism. In fact, it would be advantageous to have a fully functional VOR during head-free pursuit to help compensate for gaze disturbance produced by perturbations of the head, ${ }^{33}$ such as occur during walking or running.

In the two patients with combined cerebellar and vestibular failure there was almost total absence of any CEM response during active 
head rotations. This is consistent with the previously reported finding of the absence of any discernible COR response in two subjects with combined cerebellar and vestibular failure from our institution. ${ }^{34}$ It was therefore suggested that the cerebellum is responsible for enhancement of the normal COR in patients with vestibular failure. ${ }^{34}$ One of the subjects from the latter study (case 1) was also included in the present series, whereas the other had additional extrapyramidal and pyramidal features, suggesting a diagnosis of multiple system atrophy. As there was no reason to suspect any major cervical spine, soft tissue or spinal cord abnormality in the two patients from the present study, it could be reasonably assumed that cervical input to the vestibular nuclei should have been intact. Likewise there was no evidence of other brainstem abnormalities, a conclusion supported by the normal saccadic velocities and absence of other central neurological involvement. Connections between neck afferents and cerebellar flocculus have been demonstrated in the cat, ${ }^{35}$ and the changes that we have noted with respect to cerebellar influence on the COR may be analogous to the impaired ability to modulate the VOR seen in animals ${ }^{36}$ and in patients $^{38-41}$ with cerebellar lesions. Studies in rats have also demonstrated the importance of intact olivocerebellar pathways in the compensation of ocular position following unilateral labyrinthectomy. ${ }^{42}$ An interesting finding from an earlier study of the COR in LD subjects, where no enhancement of the COR was found, was that a number of the subjects had evidence of central neurological disturbances, such as broken smooth pursuit, which could possibly have been the result of cerebellar or brain stem disease. ${ }^{23}$ These features may have explained the absence of any COR enhancement in this patients.

The cerebellum is known to be essential for optimal pursuit performance, ${ }^{40}$ 43-45 $^{4}$ and it is of some interest that CEMs are not present above frequencies at which the pursuit response begins to break down, ${ }^{2}$ although we did not measure the higher frequency responses in our patients. It is possible that this frequency limitation may simply reflect the fact that visual feedback is required for adaptation of the COR in labyrinthine-deficient patients. What is more difficult to explain is the finding that two patients with isolated cerebellar degeneration have been shown to have an abnormally elevated COR gain. ${ }^{34}{ }^{46}$ Assuming that the features of cerebellar degeneration are of a similar nature, why should vestibular failure in addition, result in virtual absence of the CEM response? One possibility is that the primary pathology may be located in the vestibular nuclei, where cervical and pursuit inputs are known to converge in animal studies. ${ }^{47}$ This pathological pattern would be unusual, however, as there was no clinical evidence of involvement of other brain stem nuclei in our patients. Further studies are needed to determine whether the COR gain is in fact elevated in most patients with cerebellar disease before any definite conclusions can be made regarding cerebellar influences on the gain of the CEM responses.

Dr J Waterston was supported by the British Postgraduate Medical Foundation.

1 JC. Living without a balancing mechanism. $N$ Eng $\mathcal{f} \mathrm{Med}$ 1952;246:458-60.

2 Gresty MA, Hess $K$, Leech J. Disorders of the vestibuloocular reflex producing oscillopsia and mechanisms compensating for loss of labyrinthine function. Brain 1977;100:693-716.

3 Atkin A, Bender MB. Ocular stabilization during oscillatory head movements. Arch Neurol 1968;19:559-66.

4 Huygen PLM, Verhagen WIM, Theunissen EJJM, Nicolasen MGM. Compensation of total loss of vestibulo-ocular reflex by enhanced optokinetic response. Acta Otolaryngol Suppl (Stockh) 1989;468:359-64.

5 Dichgans J, Bizzi E, Morasso P, Tagliasco V. Mechanisms underlying recovery of eye-head coordination following bilateral labyrinthectomy in monkeys. Exp Brain Res 1973;18:548-62.

6 Kasai T, Zee DS. Eye-head coordination in labyrinthinedefective human beings. Brain Res 1978;144:123-41.

7 Bronstein AM, Hood JD. Oscillopsia of peripheral vestibular origin. Acta Otolaryngol (Stockh) 1987;104:307-14.

8 Bronstein AM, Hood JD. The cervico-ocular reflex in normal subjects and patients with absent vestibular function. Brain Res 1986;373:399-408.

9 Bles W, de Jong JMBV, de Wit G. Somatosensory compensation for loss of labyrinthine function. Acta Otolaryngol (Stockh) 1984;97:213-21.

10 Robinson DA. A model of cancellation of the vestibuloocular reflex. In: Lennerstrand et al, eds. Functional basis of ocular motility disorders. Oxford: Pergamon Press, of ocular $1982: 5-13$.

11 Collewign H, Conijn P, Tamminga EP. Eye-head coordination in man during the pursuit of moving targets. In: tion in man during the pursuit of moving targets. In: disorders. Oxford: Pergamon Press, 1982:369-78.

12 Barnes GR, Lawson JF. Head-free pursuit in the human of a visual target moving in a pseudo-random manner. $f$ Physiol (Lond) 1989;410:137-55.

13 Leigh RJ, Sharpe JA, Ranalli PJ, Thurston SE, Hamid MA Comparison of smooth pursuit and combined eye-head tracking in human subjects with deficient labyrinthine function. Exp Brain Res 1987;66:458-64.

14 Waterston JA, Barnes GR. Visual-vestibular interaction during head-free pursuit of pseudo-random target motion in man. ₹Vestibular Res 1992;2:71-88.

15 Barnes GR, Donnelly SF, Eason RD. Predictive velocity estimation in the pursuit reflex response to pseudoestimation in the pursuit reflex response to pseudo-
random and step displacement stimuli in man. $f$ Physiol (Lond) 1987;389:111-36.

16 Barnes GR, Ruddock CJS. Factors affecting the predictability of pseudo-random motion stimuli in the pursuit reflex of man. F Physiol (Lond) 1989;408:37-165.

17 Baloh RW, Honrubia V, Yee RD, Hess K. Changes in the human vestibulo-ocular reflex after loss of peripheral sensitivity. Ann Neurol 1984;16:222-8.

18 Furman JMR, Kamerer DB. Rotational responses in patients with bilateral caloric reduction. Acta Otolaryngol (Stockh) 1989;108:355-61.

19 Takahashi M, Uemera T, Fujishiro T. Studies of the vestibulo-ocular reflex and visual-vestibular interactions during active head movements. Acta Otolaryngol (Stockh) 1980;90:115-24.

20 Barnes GR. A procedure for the analysis of nystagmus and other eye movements. Aviat Space Environ Med 1982; 53:676-82.

21 Takahashi $M$, Uemura T, Fujishiro T. Compensatory eye movement and gaze fixation during active head rotation in patients with labyrinthine disorders. Ann Otol Rhinol Laryngol 1981;90:241-5.

22 Barnes GR. Head-eye coordination in normals and in patients with vestibular disorders. Adv Otorhinolaryngol 1979;25:197-201.

23 Leopold HC, Doerr M, Thoden U. Cervico-ocular responses (COR) during slow sinusoidal head movements in subjects with bilateral labyrinthine lesions. Arch Psychiatry Neurol Sci 1983;233:439-47.

24 Jongkees LBW. Cervical vertigo. Laryngoscope 1969;79. 1473-84.

25 Bles W, de Jong JMBV, Rasmussens JJ. Postural and oculomotor signs in labyrinthine-defective subjects. Acta Oculomotor signs in labyrinthine-defective subj

26 Gresty M, Leech J. Coordination of the head and eyes in pursuit of predictable and random target motion. Aviat pursuit of predictable and random
Space Environ Med 1977;48:741-4.

27 Grossman GE, Leigh RJ. Instability of gaze during locomotion in patients with deficient vestibular function. $A n n$ Neurol 1990;27:528-32.

28 Barnes GR, Benson AJ, Prior ARJ. Visual-vestibular interaction in the control of eye movement. Aviat Space Environ Med 1978;49:557-64.

29 Lau CGY, Honrubia V, Jenkins HA, Baloh RW, Yee RD Linear model for visual-vestibular interaction. Aviat Space Environ Med 1978;49:880-5.

30 Gauthier GM, Vercher J-L. Visual vestibular interaction: vestibulo-ocular reflex suppression with head-fixed target fixation. Exp Brain Res 1990;81:150-60.

31 Miles FA, Fuller JH. Visual tracking and the primate flocculus. Science 1975;189:1000-2. 
32 Suzuki DA, Keller EL. The role of the posterior vermis of monkey cerebellum in smooth-pursuit eye movement control. I. Eye and head movement-related activity. $\mathcal{f}$ Neurophysiol 1988;59:1-18.

33 Lanman J, Bizzi E, Allum J. The coordination of eye and head movement during smooth pursuit. Brain Res 1978;153:39-53.

34 Bronstein AM, Mossman S, Luxon LM. The neck-eye reflex in patients with reduced vestibular and optokinetic function. Brain 1991;114:1-11.

35 Wilson VJ, Maeda M, Franck JI. Input from neck afferents to the cat flocculus. Brain Res 1975;89:133-8.

36 Takemori S, Cohen B. Loss of visual suppression of vestibular nystagmus after flocculus lesions. Brain Res 1974;72:213-24.

37 Robinson DA. Adaptive gain control of vestibuloocular reflex by the cerebellum. $f$ Neurophysiol 1976;

38 Coats AC. Central electronystagmographic abnormalities. Arch Otolaryngol 1970;92:43-53.

39 Alpert $\mathrm{JN}$. Failure of fixation suppression: a pathologic effect of vision on caloric nystagmus. Neurology 1974;24:891-6.

40 Zee DS, Yee RD, Cogan DG, Robinson DA, Engel WK Ocular motor abnormalities in hereditary cerebellar ataxia. Brain 1976;99:207-34.

41 Dichgans J, von Reutern GM, Römmelt U. Impaired suppression of vestibular nystagmus by fixation in cerebellar and noncerebellar patients. Arch Psychiatry Neuro Sci 1978;226:183-99.

42 Llinás R, Walton K. Significance of the olivo-cerebellar system in compensation of ocular position following unilateral labyrinthecotomy. In: Baker R, Berthoz A, eds. Control of gaze by brain stem neurons. Amsterdam: Elsevier, 1977:399-408.

43 von Noorden GK, Preziosi TJ. Eye movement recordings in neurological disorders. Arch Ophthalmol 1966;76: 162-71.

44 Westheimer G, Blair SM. Functional organzation of primate oculomotor system revealed by cerebellectomy. Exp Brain Res 1974;21:463-72.

45 Baloh RW, Konrad HR, Honrubia V. Vestibulo-ocular function in patients with cerebellar atrophy. Neurology 1975;25:160-8.

46 Thurston SE, Leigh RJ, Abel LA, Dell'Osso LF. Hyperactive vestibulo-ocular reflex in cerebellar degeneration pathogenesis and treatment. Neurology 1987;37:53-7.

47 Rubin AM, Young JH, Milne AC, Scharz DWF, Fredrickson JM. Vestibular-neck integration in the vestibular nuclei. Brain Res 1975;96:99-102.

\section{A note on Heterochromia iridis}

"Her eyes are so adorable, but one of them is blue". . . . so runs an old Arthur Daley/Terence Christmas jingle. Sector pigmentation of one eye is common and is ascribed to persistence of the pupillary membrane. Irides of totally different colour are well known, harmless but rare. Aristotle named it heteroglaucous (Gk glaukos, sea-green). The Emperor Anastasios I probably had this condition and was generally called Dicorus. Alexander the Great was similarly affected. ${ }^{1}$
The association with deafness constitutes Waardenburg's syndrome and heterochromia iridis may be seen in congenital Horner's syndrome, the affected side being blue or depigmented in comparison with the normal side.

JMS PEARCE

1 Gladstone RM. Development and significance of heterochromia on the iris. Arch Neurol 1969;32:184-92. 